\title{
Iterative Approximation of Endpoints for Multivalued Mappings in Banach Spaces
}

\author{
Thabet Abdeljawad $\left(\mathbb{D},{ }^{1,2,3}\right.$ Kifayat Ullah, ${ }^{4}$ Junaid Ahmad $\left(\mathbb{D},{ }^{4}\right.$ and Nabil Mlaiki ${ }^{1}{ }^{1}$ \\ ${ }^{1}$ Department of Mathematics and General Sciences, Prince Sultan University, P.O. Box 66833, Riyadh 11586, Saudi Arabia \\ ${ }^{2}$ Department of Medical Research, China Medical University, Taichung 40402, Taiwan \\ ${ }^{3}$ Department of Computer Sciences and Information Engineering, Asia University, Taichung, Taiwan \\ ${ }^{4}$ Department of Mathematics, University of Science and Technology, Bannu 28100, Khyber Pakhtunkhwa, Pakistan
}

Correspondence should be addressed to Junaid Ahmad; ahmadjunaid436@gmail.com

Received 12 July 2019; Revised 15 October 2019; Accepted 11 December 2019; Published 22 January 2020

Academic Editor: Adrian Petrusel

Copyright ( 2020 Thabet Abdeljawad et al. This is an open access article distributed under the Creative Commons Attribution License, which permits unrestricted use, distribution, and reproduction in any medium, provided the original work is properly cited.

\begin{abstract}
The purpose of this paper is to introduce the modified Agarwal-O'Regan-Sahu iteration process (S-iteration) for finding endpoints of multivalued nonexpansive mappings in the setting of Banach spaces. Under suitable conditions, some weak and strong convergence results of the iterative sequence generated by the proposed process are proved. Our results especially improve and unify some recent results of Panyanak (J. Fixed Point Theory Appl. (2018)). At the end of the paper, we offer an example to illustrate the main results.
\end{abstract}

\section{Introduction and Preliminaries}

Throughout this paper, $\mathbb{N}$ stands for the set of natural numbers, and $\mathbb{R}$ stands for the set of real numbers. Let $X=$ $(X,\|\cdot\|)$ be a Banach space and $C$ be a nonempty subset of $X$. For $x \in X$, set

$$
\begin{aligned}
\operatorname{dist}(x, C) & =\inf \{\|x-y\|: y \in C\}, \\
D(x, C) & =\sup \{\|x-y\|: y \in C\} .
\end{aligned}
$$

We shall denote the set of all nonempty and compact subsets of $C$ by $K(C)$. Set $H(A, B)=\max$ $\left\{\sup _{a \in A} \operatorname{dist}(a, B), \sup _{b \in B} \operatorname{dist}(b, A)\right\}$, for each $A, B \in K \quad(C) . H$ (.,.) is known as the Hausdorff metric on the set $K(C)$. A multivalued mapping $T: C \longrightarrow K(C)$ is said to be nonexpansive if

$$
H(T x, T y) \leq\|x-y\|, \text { for each } x, y \in C .
$$

A point $q \in C$ is said to be a fixed point of $T: C \longrightarrow K(C)$ if $q \in T q$ and is said to be an endpoint (or a stationary point) of $T: C \longrightarrow K(C)$ if $T q=\{q\}$. From now on, we will denote the set of all endpoints and the set of all fixed points of $T$ by $E_{T}$ and $F_{T}$, respectively. Note that, a multivalued mapping $T: C \longrightarrow K(C)$ is said to satisfy the endpoint condition [1] if $E_{T}=F_{T}$. Different iteration processes have been developed to approximate the fixed points of multivalued mappings. Keep in mind, Sastry and Babu [2] proved Mann and Ishikawa-type convergence results for multivalued nonexpansive mappings in the framework of Hilbert spaces. Panyanak [3] extended the results of Sastry and Babu [2] to the framework of uniformly convex Banach spaces. Actually, Panyanak [3] showed some results using Ishikawa-type iteration process without the endpoint condition. Song and Wang [4] showed that without the endpoint condition, their process was not well-defined. They reconstructed the process using the endpoint condition which made it well-defined. After this, Shahzad and Zegeye [5] introduced two types of Ishikawa iterations. Note that, their first type iteration also requires the endpoint condition.

For a multivalued mapping $T: C \longrightarrow K(C)$, if $q \in C$ is an endpoint of $T$, then $q$ is also a fixed point of $T$; but the converse is not always true (see the following example). 
Example 1. Let $C=[0,1]$. Define $T: C \longrightarrow K(C)$ by

$$
T(x)=\left[0, x^{2}\right] \text { for each } x \in C .
$$

Cleary $E_{T}=\{0\}$ and $F_{T}=\{0,1\}$.

For existence results of endpoints of multivalued mappings in the framework of Banach spaces, see [6-12]. Very recently, Panyanak [13] used an Ishikawa-type iteration process to approximate endpoints of multivalued nonexpansive mappings in the setting of Banach spaces.

Agarwal et al. [14] introduced an iteration process known as S-iteration process, which is independent of both Mann [15] and Ishikawa [16] iterations, for a single-valued mappings in Banach spaces:

$$
\left\{\begin{array}{l}
x_{1} \in C \\
y_{n}=\beta_{n} T x_{n}+\left(1-\beta_{n}\right) x_{n}, \\
x_{n+1}=\alpha_{n} T y_{n}+\left(1-\alpha_{n}\right) T x_{n} \\
n \in \mathbb{N},
\end{array}\right.
$$

where $\alpha_{n}, \beta_{n} \in[0,1]$. They proved that the rate of convergence of iteration process (4) is the same as Picard iteration process $x_{n+1}=T x_{n}$ and faster than Mann [15] iteration process for the class of contraction mappings. Later, it was observed that this scheme also converges faster than Ishikawa [16] iteration process (see e.g., [17]; for more details and some recent literature of S-iteration process, see [18-24]).

Keeping above in mind, we introduce our iteration process as follows:

$$
\left\{\begin{array}{l}
x_{1} \in C, \\
y_{n}=\beta_{n} u_{n}+\left(1-\beta_{n}\right) x_{n}, \\
x_{n+1}=\alpha_{n} v_{n}+\left(1-\alpha_{n}\right) u_{n}, \\
n \in \mathbb{N},
\end{array}\right.
$$

where $u_{n} \in T x_{n}$ such that $\left\|x_{n}-u_{n}\right\|=D\left(x_{n}, T x_{n}\right)$ and $v_{n} \in T y_{n}$ such that $\left\|y_{n}-v_{n}\right\|=D\left(y_{n}, T y_{n}\right)$.

In this way, we approximate endpoints of multivalued nonexpansive mappings by an iteration process which is independent of but faster than Ishikawa iteration process. Thus, our results improve and unify corresponding results of Panyanak [13] and references therein.

Definition 1. A Banach space $X$ is said to be uniformly convex if for each $\varepsilon \in(0,2]$, there is a $\lambda>0$ such that for every $x, y \in X$,

$$
\left.\begin{array}{l}
\|x\| \leq 1 \\
\|y\| \leq 1 \\
\|x-y\|>\varepsilon
\end{array}\right\} \Longrightarrow \frac{1}{2}\|x+y\| \leq(1-\lambda) .
$$

Definition 2 (see [25]). A Banach space $X$ is said to have Opial's property if for each sequence $\left\{x_{n}\right\}$ in $X$ which weakly converges to $x \in X$ and for every $y \in X-\{x\}$, it follows that

$$
\limsup _{n \rightarrow \infty}\left\|x_{n}-x\right\|<\limsup _{n \rightarrow \infty}\left\|x_{n}-y\right\| .
$$

Examples of Banach spaces satisfying this condition are Hilbert spaces and all $l^{p}$ spaces $(1<p<\infty)$.

Definition 3 (see [13]). Let $C$ be a nonempty subset of a Banach space $X$. A mapping $T: C \longrightarrow K(C)$ is said to satisfy condition $(J)$ if there is a nondecreasing function $g:[0, \infty) \longrightarrow[0, \infty)$ with $g(0)=0, g(t)>0$ for $t \in(0, \infty)$ such that

$$
D(x, T x) \geq g\left(\operatorname{dist}\left(x, E_{T}\right)\right),
$$

for each $x \in C$.

Definition 4 (see [13]). Let $C$ be a nonempty subset of a Banach space $X$. A mapping $T: C \longrightarrow K(C)$ is said to be semicompact if for every sequence $\left\{x_{n}\right\}$ in $C$ such that

$$
\lim _{n \rightarrow \infty} D\left(x_{n}, T x_{n}\right)=0 \text {, }
$$

there is a subsequence $\left\{x_{n_{j}}\right\}$ of $\left\{x_{n}\right\}$ such that $\lim _{j \rightarrow \infty} x_{n_{j}}=p$ for some $p \in C$. We see that, if $C$ is compact then every multivalued mapping $T: C \longrightarrow K(C)$ is semicompact.

Definition 5. Let $C$ be a nonempty subset of a Banach space $X \mathrm{~A}$ sequence $\left\{x_{n}\right\}$ in $X$ is called Fejer-monotone with respect to $C$ if

$$
\left\|x_{n+1}-c\right\| \leq\left\|x_{n}-c\right\|,
$$

for each $c \in C$ and $n \in \mathbb{N}$.

The following important lemma is due to $\mathrm{Xu}$ [26].

Lemma 1. A Banach space $X$ is uniformly convex if and only if for any number $k>0$, and there is a strictly increasing and continuous function $\psi:[0, \infty) \longrightarrow[0, \infty)$ with $\psi(0)=0$ such that

$$
\|\alpha x+(1-\alpha) y\|^{2} \leq \alpha\|x\|^{2}+(1-\alpha)\|y\|^{2}-\alpha(1-\alpha) \psi(\|x-y\|),
$$

for each $x, y \in X$ with $\|x\| \leq k,\|y\| \leq k$, and $\alpha \in[0,1]$.

The following lemma can be found in [13].

Lemma 2. For a multivalued mapping $T: C \longrightarrow K(C)$, the following statements hold.

(a) $\operatorname{dist}(x, T x)=0 \Longleftrightarrow x$ is a fixed point of $T$

(b) $D(x, T x)=0 \Longleftrightarrow x$ is an endpoint of $T$

(c) If $T$ is nonexpansive, then the mapping $h: C \longrightarrow \mathbb{R}$ defined by $h(x)=D(x, T x)$ is continuous

Lemma 3 (see [3]). Let $\left\{\alpha_{n}\right\},\left\{\beta_{n}\right\}$ be two real sequences such that
(a) $0 \leq \alpha_{n}, \beta_{n}<1$
(b) $\lim _{n \longrightarrow \infty} \beta_{n}=0$
(c) $\sum \alpha_{n} \beta_{n}=\infty$ 
Let $\left\{\gamma_{n}\right\}$ be a sequence of nonnegative real numbers such that $\sum \alpha_{n} \beta_{n}\left(1-\beta_{n}\right) \gamma_{n}<\infty$, then $\left\{\gamma_{n}\right\}$ has a subsequence which converges to 0 .

Lemma 4 (see [27]). Let $C$ be a nonempty closed and convex subset of a uniformly convex Banach space and $T: C \longrightarrow K(C)$ be a multivalued nonexpansive mapping. Then, the following is true:

$$
\begin{gathered}
\left\{x_{n}\right\} \subseteq C, \\
x_{n} \rightarrow x, \\
D\left(x_{n}, T x_{n}\right) \longrightarrow 0 \Longrightarrow x \in E_{T} .
\end{gathered}
$$

The following fact is needed which can be found in [28].

Proposition 1. Let $C$ be a nonempty closed subset of a Banach space. Let $\left\{x_{n}\right\}$ be a Fejer-monotone sequence with respect to $C$. Then, $\left\{x_{n}\right\}$ converges (strongly) to the point of $C$ if and only if $\lim _{n \longrightarrow \infty} \operatorname{dist}\left(x_{n}, C\right)=0$.

\section{Main Results}

The following lemma is crucial.

Lemma 5. Let $C$ be a nonempty closed convex subset of a uniformly convex Banach space $X$ and $T: C \longrightarrow K(C)$ be a multivalued nonexpansive mapping with $E_{T} \neq \varnothing$. Let $\left\{x_{n}\right\}$ be a sequence defined by (5). Then, $\lim _{n \longrightarrow \infty}\left\|x_{n}-q\right\|$ exists for each $q \in E_{T}$.

Proof. Let $q \in E_{T}$. For each $n \in \mathbb{N}$, we have

$$
\begin{aligned}
\left\|y_{n}-q\right\| & \leq \beta_{n}\left\|u_{n}-q\right\|+\left(1-\beta_{n}\right)\left\|x_{n}-q\right\| \\
& \leq \beta_{n} \operatorname{dist}\left(u_{n}, T q\right)+\left(1-\beta_{n}\right)\left\|x_{n}-q\right\| \\
& \leq \beta_{n} H\left(T x_{n}, T q\right)+\left(1-\beta_{n}\right)\left\|x_{n}-q\right\| \\
& \leq \beta_{n}\left\|x_{n}-q\right\|+\left(1-\beta_{n}\right)\left\|x_{n}-q\right\| \\
& \leq\left\|x_{n}-q\right\|,
\end{aligned}
$$

which implies that

$$
\begin{aligned}
\left\|x_{n+1}-q\right\| & \leq \alpha_{n}\left\|v_{n}-q\right\|+\left(1-\alpha_{n}\right)\left\|u_{n}-q\right\| \\
& \leq \alpha_{n} \operatorname{dist}\left(v_{n}, T q\right)+\left(1-\alpha_{n}\right) \operatorname{dist}\left(u_{n}, T q\right) \\
& \leq \alpha_{n} H\left(T y_{n}, T q\right)+\left(1-\alpha_{n}\right) H\left(T x_{n}, T q\right) \\
& \leq \alpha_{n}\left\|y_{n}-q\right\|+\left(1-\alpha_{n}\right)\left\|x_{n}-q\right\| \\
& \leq\left\|x_{n}-q\right\| .
\end{aligned}
$$

Hence, $\left\{\left\|x_{n}-q\right\|\right\}$ is a nonincreasing sequence, which implies $\lim _{n \longrightarrow \infty}\left\|x_{n}-q\right\|$ exists for all $q \in E_{T}$.

First, we prove our weak convergence result.

Theorem 1. Let $X$ be a uniformly convex Banach space with the Opial property, $C$ be a nonempty closed convex subset of $X$, and $T: C \longrightarrow K(C)$ be a multivalued nonexpansive mapping with $E_{T} \neq \varnothing$. Let $\alpha_{n}, \beta_{n} \in[a, b] \subset(0,1)$ and $\left\{x_{n}\right\}$ be a sequence defined by (5). Then, $\left\{x_{n}\right\}$ converges weakly to an element of $E_{T}$.
Proof. Fix $q \in E_{T}$. By Lemma 1., there exists a strictly increasing continuous function $\psi:[0, \infty) \longrightarrow[0, \infty)$ with $\psi(0)=0$ such that

$$
\begin{aligned}
\left\|y_{n}-q\right\|^{2}= & \left\|\beta_{n} u_{n}+\left(1-\beta_{n}\right) x_{n}-q\right\|^{2} \\
\leq & \beta_{n}\left\|u_{n}-q\right\|^{2}+\left(1-\beta_{n}\right)\left\|x_{n}-q\right\|^{2}-\beta_{n}\left(1-\beta_{n}\right) \psi \\
& \cdot\left(\left\|u_{n}-x_{n}\right\|\right) \\
\leq & \beta_{n} H^{2}\left(T x_{n}, T q\right)+\left(1-\beta_{n}\right)\left\|x_{n}-q\right\|^{2}-\beta_{n}\left(1-\beta_{n}\right) \\
& \psi\left(\left\|u_{n}-x_{n}\right\|\right) \\
\leq & \beta_{n}\left\|x_{n}-q\right\|^{2}+\left(1-\beta_{n}\right)\left\|x_{n}-q\right\|^{2}-\beta_{n}\left(1-\beta_{n}\right) \psi \\
& \cdot\left(\left\|u_{n}-x_{n}\right\|\right) \\
\leq & \left\|x_{n}-q\right\|^{2}-\beta_{n}\left(1-\beta_{n}\right) \psi\left(\left\|u_{n}-x_{n}\right\|\right) .
\end{aligned}
$$

Thus,

$$
\begin{aligned}
\left\|x_{n+1}-q\right\|^{2}= & \left\|\alpha_{n} v_{n}+\left(1-\alpha_{n}\right) u_{n}-q\right\|^{2} \\
\leq & \alpha_{n}\left\|v_{n}-q\right\|^{2}+\left(1-\alpha_{n}\right)\left\|u_{n}-q\right\|^{2}-\alpha_{n}\left(1-\alpha_{n}\right) \psi \\
& \cdot\left(\left\|v_{n}-u_{n}\right\|\right) \\
\leq & \alpha_{n} H^{2}\left(T y_{n}, T q\right)+\left(1-\alpha_{n}\right) H^{2}\left(T x_{n}, T q\right)-\alpha_{n} \\
& \cdot\left(1-\alpha_{n}\right) \psi\left(\left\|v_{n}-u_{n}\right\|\right) \\
\leq & \alpha_{n}\left\|y_{n}-q\right\|^{2}+\left(1-\alpha_{n}\right)\left\|x_{n}-q\right\|^{2}-\alpha_{n}\left(1-\alpha_{n}\right) \psi \\
& \cdot\left(\left\|v_{n}-u_{n}\right\|\right) \\
\leq & \alpha_{n}\left\|y_{n}-q\right\|^{2}+\left(1-\alpha_{n}\right)\left\|x_{n}-q\right\|^{2} \\
\leq & \alpha_{n}\left\|x_{n}-q\right\|^{2}+\left(1-\alpha_{n}\right)\left\|x_{n}-q\right\|^{2}-\alpha_{n} \beta_{n}\left(1-\beta_{n}\right) \\
& \psi\left(\left\|u_{n}-x_{n}\right\|\right) .
\end{aligned}
$$

It follows that

$$
\sum_{n=1}^{\infty} a^{2}(1-b) \psi\left(\left\|u_{n}-x_{n}\right\|\right) \leq \sum_{n=1}^{\infty} \alpha_{n} \beta_{n}\left(1-\beta_{n}\right) \psi\left(\left\|u_{n}-x_{n}\right\|\right)<\infty .
$$

Thus, $\lim _{n \rightarrow \infty} \psi\left(\left\|u_{n}-x_{n}\right\|\right)=0$. But $\psi$ is strictly increasing and continuous, we have $\lim _{n \longrightarrow \infty}\left\|u_{n}-x_{n}\right\|=0$. Hence,

$$
\lim _{n \longrightarrow \infty} D\left(x_{n}, T x_{n}\right)=\lim _{n \longrightarrow \infty}\left\|u_{n}-x_{n}\right\|=0 .
$$

To show that $\left\{x_{n}\right\}$ converges weakly to an element of $E_{T}$, it suffices to show that $\left\{x_{n}\right\}$ has a unique weak subsequential limit in $E_{T}$. For this purpose, we assume that there are subsequences $\left\{x_{n_{m}}\right\}$ and $\left\{x_{n_{k}}\right\}$ of $\left\{x_{n}\right\}$ such that $x_{n_{m}} \rightarrow u$ and $x_{n_{k}} \rightarrow v$. By (18), $\lim _{m \longrightarrow \infty} D\left(x_{n_{m}}, T x_{n_{m}}\right)=0$. By Lemma 4, $u \in E_{T}$. Similarly, it can be shown that $v \in E_{T}$. Next, we prove $u=v$. On the contrary suppose $u \neq v$, then by Lemma 5 together withOpial's property, we have 


$$
\begin{aligned}
\lim _{n \longrightarrow \infty}\left\|x_{n}-u\right\| & =\lim _{m \rightarrow \infty}\left\|x_{n_{m}}-u\right\| \\
& <\lim _{m \rightarrow \infty}\left\|x_{n_{m}}-v\right\| \\
& =\lim _{n \longrightarrow \infty}\left\|x_{n}-v\right\| \\
& =\lim _{k \longrightarrow \infty}\left\|x_{n_{k}}-v\right\| \\
& <\lim _{k \longrightarrow \infty}\left\|x_{n_{k}}-u\right\| \\
& =\lim _{n \rightarrow \infty}\left\|x_{n}-u\right\|,
\end{aligned}
$$

which is a contradiction. So, $u=v$. Hence proved.

Now, we approximate endpoints of the mapping $T$ through strong convergence of the sequence $\left\{x_{n}\right\}$ defined by (5).

Theorem 2. Let $C$ be a nonempty closed convex subset of a uniformly convex Banach space $X$ and $T: C \longrightarrow K(C)$ be a multivalued nonexpansive mapping with $E_{T} \neq \varnothing$. Let $\alpha_{n}, \beta_{n} \in[0,1)$ be such that $\lim _{n \longrightarrow \infty} \beta_{n}=0$ and $\sum \alpha_{n} \beta_{n}=\infty$ and let $\left\{x_{n}\right\}$ be a sequence defined by (5). If T is semicompact, then $\left\{x_{n}\right\}$ converges strongly to an element of $E_{T}$.

Proof. In view of (17),

$$
\sum_{n=1}^{\infty} \alpha_{n} \beta_{n}\left(1-\beta_{n}\right) \psi\left(\left\|u_{n}-x_{n}\right\|\right)<\infty .
$$

By Lemma 3, subsequences $\left\{u_{n_{j}}\right.$
$\left\{x_{n}\right\} \quad$ exists, respectively, and $\left\{\begin{array}{c}\left.x_{n_{j}}\right\} \text { of }\left\{u_{n}\right\} \text { and } \\ \text { such }\end{array}\right.$ $\lim _{j \longrightarrow \infty} \psi\left(\left\|u_{n_{j}}-x_{n_{j}}\right\|\right)=0$. Since $\psi$ is strictly increasing and continuous, we have $\lim _{j \longrightarrow \infty}\left\|u_{n_{j}}-x_{n_{j}}\right\|=0$. Hence,

$$
\lim _{j \longrightarrow \infty} D\left(x_{n_{j}}, T x_{n_{j}}\right)=\lim _{j \longrightarrow \infty}\left\|u_{n_{j}}-x_{n_{j}}\right\|=0 .
$$

On the contrary, $T$ is semicompact; we may choose by passing through a subsequence that $\lim _{j \longrightarrow \infty} x_{n_{j}}=p$ for some $p \in C$. We need to show $p \in E_{T}$ and $x_{n} \rightarrow p$. By Lemma 2 part (c), together with (21), we have

$$
D(p, T p)=\lim _{j \longrightarrow \infty} D\left(x_{n_{j}}, T x_{n_{j}}\right)=0 .
$$

It follows from Lemma 2 part (b) that $p \in E_{T}$. By Lemma $5, \lim _{n \longrightarrow \infty}\left\|x_{n}-p\right\|$ exists, and hence $p$ is the strong limit of $\left\{x_{n}\right\}$.

In the next strong convergence result, we relax semicompactness of $T$ with the help of condition $(J)$.

Theorem 3. Let $C$ be a nonempty closed convex subset of a uniformly convex Banach space $X$ and $T: C \longrightarrow K(C)$ be a multivalued nonexpansive mapping with $E_{T} \neq \varnothing$. Let $\alpha_{n}, \beta_{n} \in[a, b] \subset(0,1)$ and $\left\{x_{n}\right\}$ be a sequence defined by (5). If T satisfies condition (J), then $\left\{x_{n}\right\}$ converges strongly to an element of $E_{T}$.

Proof. Since $T$ satisfies condition ( $J$ ), by (18), we get that $\lim _{n \longrightarrow \infty} \operatorname{dist}\left(x_{n}, E_{T}\right)=0$. Closeness of $E_{T}$ follows from the nonexpansiveness of $T$. In the view of Lemma 5, we have $\left\{x_{n}\right\}$ is Fejer-monotone with respect to $E_{T}$. By Proposition 1, $\left\{x_{n}\right\}$ converges strongly to an element of $E_{T}$.
Here is an example in support of the main theorems.

Example 2. Let $X=\mathbb{R}$ and $C=[2,5]$ with absolute valued norm. Define a multivalued mapping $T: C \longrightarrow K(C)$ by $T(x)=[2, x]$ for each $x \in C$. Clearly $T$ is semicompact and nonexpansive with $E_{T}=\{2\}$. We prove that $T$ satisfies condition $(J)$ with $g(t)=t$. When $x \in C=[2,5]$, we have

$$
\begin{aligned}
g\left(\operatorname{dist}\left(x, E_{T}\right)\right) & =g(\operatorname{dist}(x,\{2\})) \\
& =g(|x-2|) \\
& =|x-2| \\
& =\sup \{|x-y|: y \in[2, x]\} \\
& =D(x,[2, x]) \\
& =D(x, T x) .
\end{aligned}
$$

Next, we prove that $\left\{x_{n}\right\}$ defined by (5) strongly converges to 2 .

Choose $\alpha_{n}=\beta_{n}=(1 / \sqrt{n+1})$, for all $n \in \mathbb{N}$. Let $x_{1}=3$, then $T\left(x_{1}\right)=[2,3]$. Take $u_{1} \in[2,3]$ such that;

$$
\begin{aligned}
\left|3-u_{1}\right| & =D(3, T(3)) \\
& =D(3,[2,3]) \\
& =\sup \{|3-y|: y \in[2,3]\} \\
& =|3-(2)| .
\end{aligned}
$$

That is, $u_{1}=2$. So,

$$
\begin{aligned}
y_{1} & =\beta_{1} u_{1}+\left(1-\beta_{1}\right) x_{1} \\
& =\frac{1}{\sqrt{2}}(2)+\left(1-\frac{1}{\sqrt{2}}\right)(3) \\
& =3-\frac{1}{\sqrt{2}}
\end{aligned}
$$

Now, $T\left(y_{1}\right)=[2,3-(1 / \sqrt{2})]$. Choose $v_{1} \in T y_{1}$ such that $\left|y_{1}-v_{1}\right|=D\left(y_{1}, T y_{1}\right)$. Similar calculation to the above gives $v_{1}=2$. Hence,

$$
\begin{aligned}
x_{2} & =\alpha_{1} v_{1}+\left(1-\alpha_{1}\right) u_{1} \\
& =\frac{1}{\sqrt{2}}(2)+\left(1-\frac{1}{\sqrt{2}}\right)(2) \\
& =2 .
\end{aligned}
$$

Continuing in this manner, $x_{n}=2$, for all $n \geq 2$, and hence $\left\{x_{n}\right\}$ converges strongly to $2 \in E_{T}$.

Remark 1. We see in Example 2. that, $E_{T}=\{2\}$ and $F_{T}=C$, i.e., $T$ does not satisfy the endpoint condition. Therefore, we cannot directly apply any result in $[19,22,23]$.

\section{Data Availability}

No data were used to support this study. 


\section{Conflicts of Interest}

The authors declare that they have no conflicts of interest.

\section{Authors' Contributions}

All authors contributed equally and significantly in writing this article. All authors read and approved the final manuscript.

\section{Acknowledgments}

The first and the fourth authors would like to thank Prince Sultan University for funding this work through research group Nonlinear Analysis Methods in Applied Mathematics (NAMAM) (group number RG-DES-2017-01-17).

\section{References}

[1] S. Dhompongsa, A. Kaewkhao, and B. Panyanak, "Browder's convergence theorem for multivalued mappings without endpoint condition," Topology and its Applications, vol. 159, no. 10-11, pp. 2757-2763, 2012.

[2] K. P. R. Sastry and G. V. R. Babu, "Convergence of Ishikawa iterates for a multi-valued mapping with a fixed point," Czechoslovak Mathematical Journal, vol. 55, no. 4, pp. 817826, 2005.

[3] B. Panyanak, "Mann and Ishikawa iterative processes for multivalued mappings in Banach spaces," Computers \& Mathematics with Applications, vol. 54, no. 6, pp. 872-877, 2007.

[4] Y. Song and H. Wang, "Erratum to, "Mann and Ishikawa iterative processes for multivalued mappings in Banach spaces"," Computers \& Mathematics with Applications, vol. 55, no. 12, pp. 2999-3002, 2008.

[5] N. Shahzad and H. Zegeye, "On Mann and Ishikawa iteration schemes for multi-valued maps in Banach spaces," Nonlinear Analysis: Theory, Methods \& Applications, vol. 71, no. 3-4, pp. 838-844, 2009.

[6] J.-P. Aubin and J. Siegel, "Fixed points and stationary points of dissipative multivalued maps," Proceedings of the American Mathematical Society, vol. 78, no. 3, p. 391, 1980.

[7] L. Chen, L. Gao, and D. Chen, "Fixed point theorems of mean nonexpansive set-valued mappings in Banach spaces," Journal of Fixed Point Theory and Applications, vol. 19, no. 3, pp. 2129-2143, 2017.

[8] R. Espinola, M. Hosseini, and K. Nourouzi, "On stationary points of nonexpansive set-valued mappings," Fixed Point Theory and Applications, vol. 236, pp. 1-13, 2015.

[9] M. Hosseini, K. Nourouzi, and D. O’Regan, "Stationary points of set-valued contractive and nonexpansive mappings on ultrametric spaces," Fixed Point Theory, vol. 19, no. 2, pp. 587-594, 2018.

[10] B. Panyanak, "Endpoints of multivalued nonexpansive mappings in geodesic spaces," Fixed Point Theory and Applications, vol. 147, pp. 1-11, 2015.

[11] S. Reich, "Fixed points of contractive functions," Bollettino dell'Unione Matematica Italiana, vol. 5, pp. 26-42, 1972.

[12] S. Saejung, "Remarks on endpoints of multivalued mappings on geodesic spaces," Fixed Point Theory and Applications, vol. 52, pp. 1-12, 2016.
[13] B. Panyanak, "Approximating endpoints of multi-valued nonexpansive mappings in Banach spaces," Journal of Fixed Point Theory and Applications, vol. 20, no. 2, 2018.

[14] R. P. Agarwal, D. O'Regan, and D. R. Sahu, "Iterative construction of fixed points of nearly asymptotically nonexpansive mappings," Journal of Nonlinear and Convex Analysis, vol. 8, no. 1, pp. 61-79, 2007.

[15] W. R. Mann, "Mean value methods in iteration," Proceedings of the American Mathematical Society, vol. 4, no. 3, p. 506, 1953.

[16] S. Ishikawa, "Fixed points by a new iteration method," Proceedings of the American Mathematical Society, vol. 44, no. 1, p. $147,1974$.

[17] S. H. Khan and J.-K. Kim, "Common fixed points of two nonexpansive mappings by a modified faster iteration scheme," Bulletin of the Korean Mathematical Society, vol. 47, no. 5, pp. 973-985, 2010.

[18] S. Aggarwal, I. Uddin, and J. J. Nieto, “A fixed point theorem for monotone nearly asymptotically nonexpansive mappings," Journal of Fixed Point Theory and Applications, vol. 21, pp. 1-11, 2019.

[19] N. Akkasriworn and K. Sokhuma, "S-iterative process for a pair of single valued and multi valued mappings in Banach spaces," Thai Journal of Mathematics, vol. 14, pp. 21-30, 2016.

[20] A. Phon-on, N. Makaje, A. Sama-Ae, and K. Khongraphan, "An inertial S-iteration process," Fixed Point Theory and Applications, vol. 4, pp. 1-14, 2019.

[21] D. R. Sahu, A. Pitea, and M. Verma, "A new iteration technique for nonlinear operators as concerns convex programming and feasibility problems," Numerical Algorithms, 2019.

[22] K. Sokhuma, "S-iterative process for a pair of single valued and multi-valued nonexpansive mappings," International Mathematical Forum, vol. 7, pp. 839-847, 2012.

[23] S. Sopha and W. Phuengrattana, "Convergence of the S-iteration process for a pair of single-valued and multi-valued generalized nonexpansive mappings in CAT $(\kappa)$ spaces," Thai Journal of Mathematics, vol. 13, pp. 627-640, 2015.

[24] R. Suparatulatorn, W. Cholamjiak, and S. Suantai, "A modified S-iteration process for G-nonexpansive mappings in Banach spaces with graphs," Numerical Algorithms, vol. 77, no. 2, pp. 479-490, 2018.

[25] Z. Opial, "Weak convergence of the sequence of successive approximations for nonexpansive mappings," Bulletin of the American Mathematical Society, vol. 73, no. 4, pp. 591-598, 1967.

[26] H.-K. Xu, "Inequalities in Banach spaces with applications," Nonlinear Analysis: Theory, Methods \& Applications, vol. 16, no. 12, pp. 1127-1138, 1991.

[27] B. Panyanak, "The demiclosed principle for multi-valued nonexpansive mappings in Banach spaces," Journal of Nonlinear and Convex Analysis, vol. 17, pp. 2063-2070, 2016.

[28] P. Chuadchawna, A. Farajzadeh, and A. Kaewcharoen, "Convergence theorems and approximating endpoints for multivalued Suzuki mappings in hyperbolic spaces," J. Comp. Anal. Appl. vol. 28, pp. 903-916, 2020. 


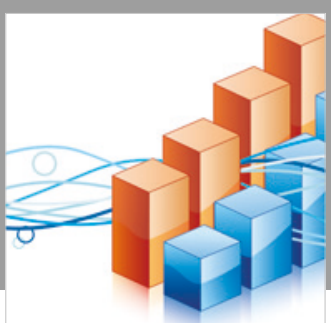

Advances in

Operations Research

\section{-n-m}
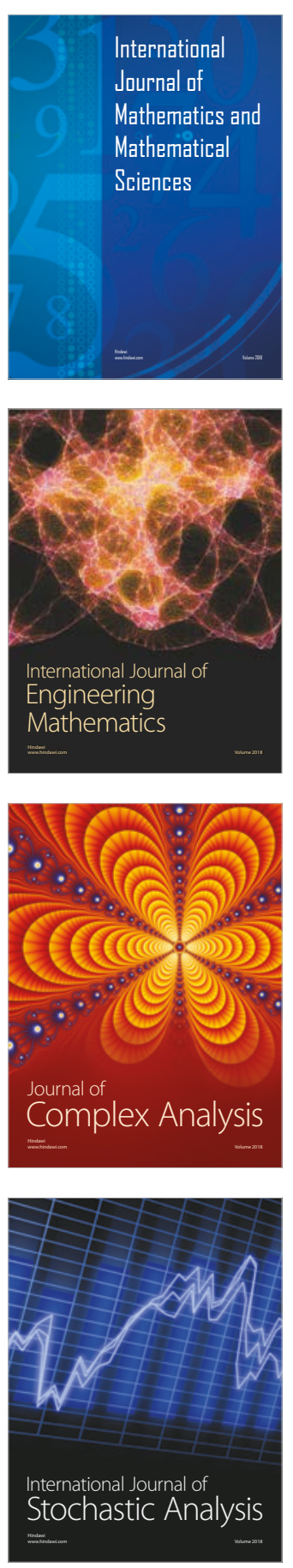
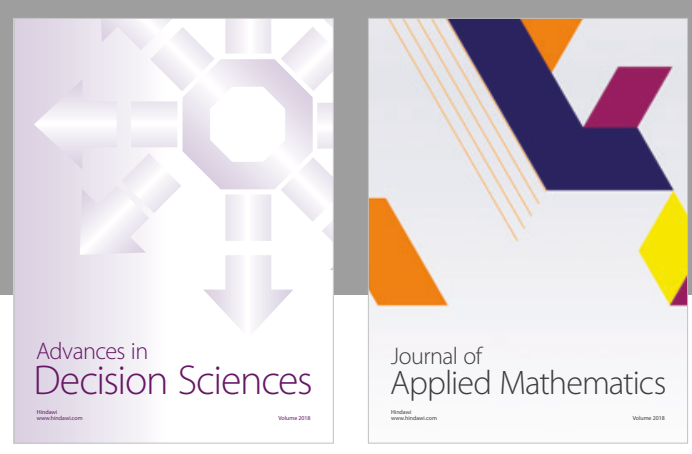

Journal of

Applied Mathematics
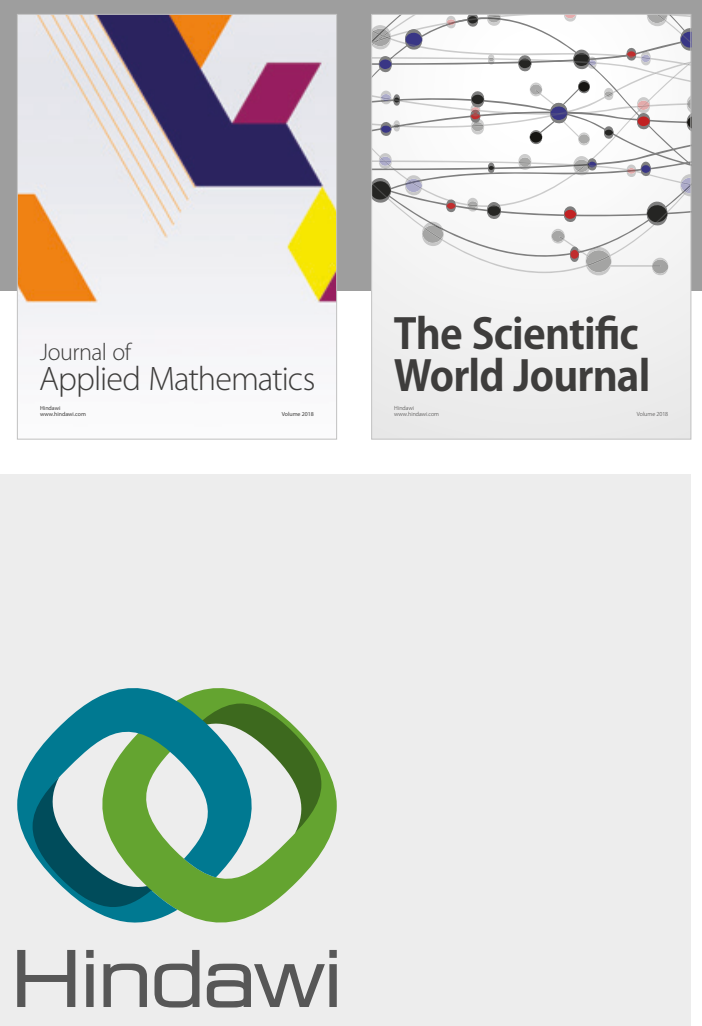

Submit your manuscripts at

www.hindawi.com

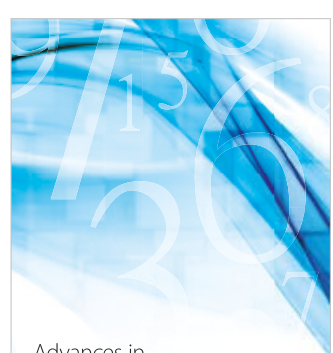

Advances in
Numerical Analysis
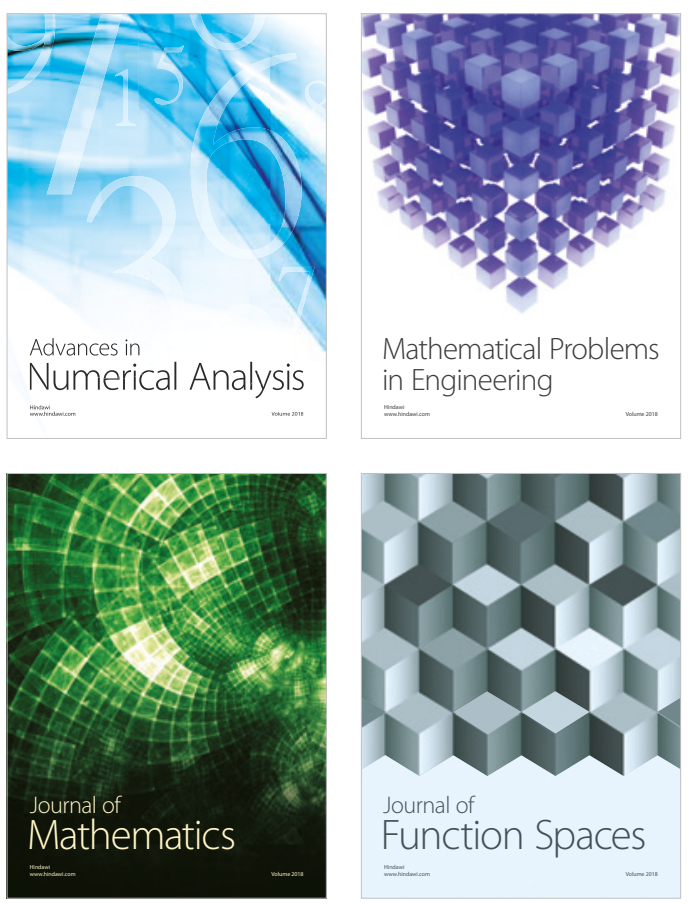

Mathematical Problems in Engineering

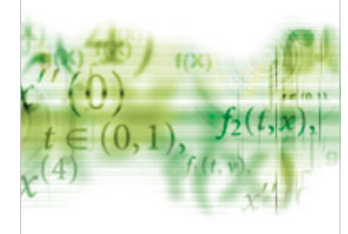

International Journal of

Differential Equations

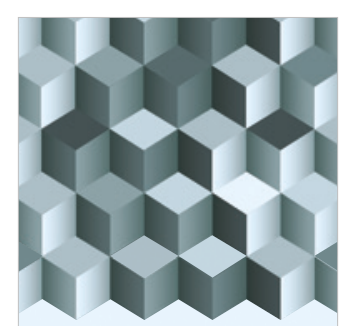

Journal of

Function Spaces

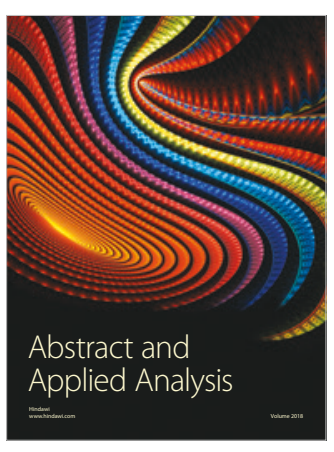

The Scientific

World Journal

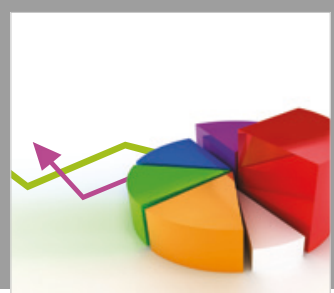

Journal of

Probability and Statistics
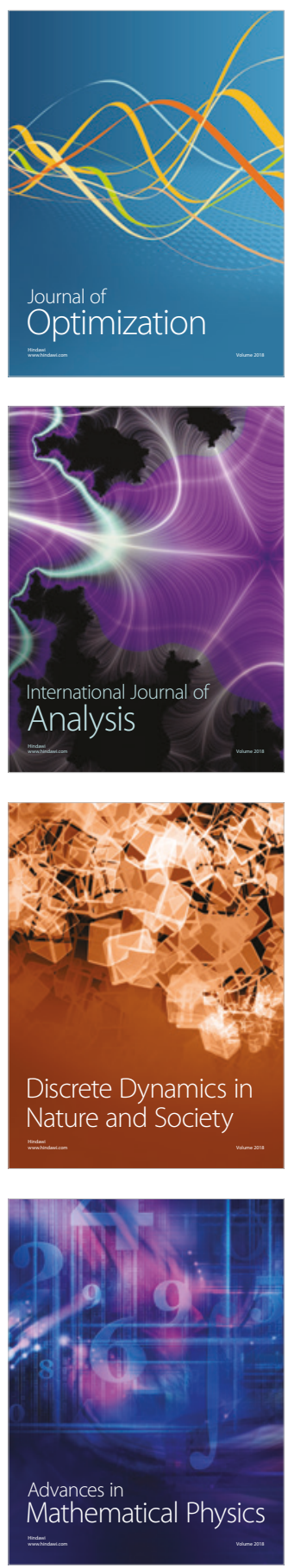